DOI 10.7764/rcia.v45i3.1930

\title{
RESEARCH PAPER \\ Perceived quality of and satisfaction from sweet cherries (Prunus avium L.) in China: Confirming relationships through structural equations
}

\author{
Andrés Chiang ${ }^{1}$, Berta Schnettler ${ }^{2}$, Marcos Mora ${ }^{3}$, and Mauricio Aguilera ${ }^{4}$ \\ ${ }^{1}$ Universidad de Chile, Facultad de Ciencias Agronómicas, Departamento de Economía Agraria, Programa \\ de Doctorado CSAV. Santa Rosa 11315, La Pintana, Santiago, Chile. \\ ${ }^{2}$ Universidad de La Frontera, Facultad de Ciencias Agropecuarias y Forestales, Departamento de \\ Producción Agropecuaria. Casilla 54-D, Temuco, Chile. \\ ${ }^{3}$ Universidad de Chile, Facultad de Ciencias Agronómicas, Departamento de Economía Agraria. Santa Rosa \\ 11315, La Pintana, Santiago, Chile. \\ ${ }^{4}$ Universidad de La Serena, Facultad de Ingeniería, Departamento de Ingeniería Industrial. Casilla 554, La \\ Serena, Chile.
}

\begin{abstract}
A. Chiang, B. Schnettler, M. Mora, and M. Aguilera. 2018. Perceived quality and satisfaction with sweet cherries (Prunus Avium L.) in China: Confirming relationships through structural equations. Cien. Inv. Agr. 45(3): 210-219. In recent years, Chile has been the Chinese market's main supplier of fresh sweet cherries. The aim of this study was to develop a relational model with two working hypotheses to model Chinese consumer satisfaction with sweet cherries as a result of the quality perceived by intrinsic and extrinsic attributes. One hundred and ninety-three buyers in the Sanyuanli Market in the Chaoyang District, Beijing, were surveyed using closed-ended questions on a Likert scale. To develop a model that fulfilled the indicated objective, an exploratory factor analysis and a subsequent system of structural equations were used to confirm the relationships, presenting an adequate goodness-of-fit test to accept the model according to the literature. Among the main results, it was determined that consumer satisfaction with sweet cherries is explained by the perceived intrinsic quality, where medium size and color are the determining attributes, and the product price, Chilean origin and delivery time explain the perceived extrinsic quality (critical ratio of 2.937 and p-value of 0.003 ). Finally, the intrinsic quality positively and significantly influences Chinese consumer satisfaction with sweet cherries, in contrast to the results for perceived extrinsic quality, which are not statistically significant.
\end{abstract}

Key words: Perceived quality, satisfaction, structural equations modeling, sweet cherries.

\section{Introduction}

Chile has become the main supplier of fresh sweet cherries to the Chinese market in recent

Received Jan 19, 2018. Accepted Ago 31, 2018.

Corresponding author: achiang@ug.uchile.cl years (ProChile, 2012), and the tonnage of sweet cherries exported in 2016 tripled over 2012 (ODEPA, 2017). Chile's strategy seems to not use knowledge of the Chinese consumer but rather market opportunities. Since the behavior of Chinese consumers is not considered in food issues, information regarding this behavior con- 
tinues to be scarce. One of the reasons for this lack of information is that the food consumption patterns in East Asia do not seem to be easily analyzed using Western cultural models (Grunert et al., 2011, Lee et al., 2015). The imported fresh fruit market in China has undergone rapid growth since opening in 1993, despite a great price difference between imported and local fruit. Part of the Chinese population prefers expensive fruit over domestic fruit, although the population has a relatively low income and has access to an abundant supply of local fruit at a better price (Sun and Collins, 2007). One explanation is that Chinese consumers, who generally consume raw fruit as a snack (Du et al., 2017), perceives the quality of imported fruit as being better than that of domestic products (Sun and Collins, 2007). Fruit consumption is also related to health, with the focus on products that confer benefits such as improved nutrition (Sun and Collins, 2007) and lack of chemical components (Ergönül, 2013). Therefore, the motivations behind the purchase of imported fruit for personal consumption could be driven by health concerns and Confucius' principle: what a person eats and wears expresses his income level and social status (Cheng et al., 2008). Cherries and other fruits, such as peaches and apples, are used preferably as gifts, especially at the Chinese New Year, with bright wrapping that includes symbols of wealth, health or happiness (Sun, 2010).

An online auction study of cherries from Chile and New Zealand shows the importance of the perception of quality attributes, such as the size of the fruit, origin of the cherry, packaging format, reputation of the seller and price paid (Sun, 2010). There are currently four main approaches to explain perceived quality: the economics of information approach, hierarchical approaches, integrative approaches and multiattribute approaches (Ness et al., 2010; Martínez-Carrasco et al., 2012). The latter approach is used in this study. The multiattribute approach understands quality as a dichotomous phenomenon divided between intrinsic and extrinsic signals (Olson and Jacoby, 1972; Zeithaml, 1988; Verbeke et al., 2010; Mora et al., 2011; Grunert et al., 2015; Lee et al., 2015). Several authors differentiate these quality signals into two types of attributes: extrinsic and intrinsic. The so-called extrinsic attributes bear a closer relationship to the product but are, by definition, beyond its substance (Olson and Jacoby, 1972; Cheng et al., 2008; Akdeniz et al., 2013). The intrinsic attributes are properties or qualities derived from the physical composition of the product, such as the ingredients and sensory attributes, which cannot be manipulated without altering the physical properties of the product itself (Lee et al., 2015). In references to such attributes in consumer goods, a distinction is made between those products whose quality can be determined prior to the purchase (search goods) and those whose attributes can be determined only after the purchase or during consumption (Mora et al., 2011; Martínez-Carrasco et al., 2012).

Satisfaction is the consumer's response to the level of a product's or service's compliance (Oliver, 2010). Satisfaction of the consumer's needs has been defined as an overall assessment of the purchase and consumption experience (Olsen et al., 2005) and the level of compliance with the need, desire, goal or other pleasant end (Olsen, 2002). Satisfaction is considered a reflection of the degree to which the purchase of a product evokes positive feelings in terms of emotive or evaluative elements (Cronin et al., 2000). One of the most frequently studied approaches in the literature is the expectation disconfirmation theory. This theory indicates that disconfirmation is a post-purchase process in which the consumer establishes a comparison between the results obtained and previously created expectations, and it is the difference between these two principles that leads the consumer to form judgments about a product or service (Olsen, 2002; Tuu et al., 2011). Perceived quality and food satisfaction are highly correlated (Churchill and Surprenant, 1982; 
Olsen, 2002; Sanzo et al., 2003; Espejel et al., 2009; Espejel and Fandos, 2009; Ness et al., 2010). In this area, the literature has proven that perceptions of a quality product exert positive effects on satisfaction (Ness et al., 2010). If the perceived quality is greater than or equal to the expected quality, the customer will be satisfied; otherwise, if the perceived quality is less than expected, the customer will be dissatisfied (Espejel et al., 2009; Ness et al., 2010). However, most of these studies have been conducted on foods with some degree of processing, brand development or distinctive seals, such as designations of origin. In this respect, there has been a paucity of studies on primary products (Martínez-Carrasco et al., 2012). In studies conducted on the primary products of fruits and vegetables, such as peaches and tomatoes, the existence of positive and significant relationships between attributes and perceived quality have been proven (Mora et al., 2011; Martínez-Carrasco et al., 2012). No studies, however, have demonstrated the relationship between perceived quality and satisfaction in fruits such as sweet cherries, for example, which is why this study is a contribution to knowledge in this regard.

Therefore, the main aim of this study is to determine the relationship between the perceived quality of sweet cherries and Chinese consumer satisfaction. The following hypotheses were tested:

$\mathrm{H}_{1}$ : There is a positive and significant relationship between the perceived extrinsic quality of sweet cherries and Chinese consumer satisfaction.

$\mathrm{H}_{2}$ : There is a positive and significant relationship between the perceived intrinsic quality of sweet cherries and Chinese consumer satisfaction.

Both hypotheses are part of the proposed model, which endeavors to measure Chinese consumer satisfaction with sweet cherries in terms of the product's extrinsic and intrinsic qualities (Figure 1).

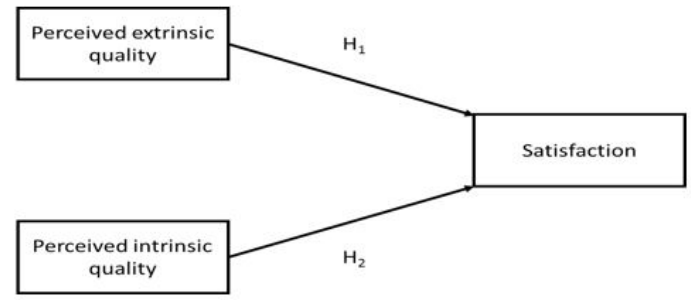

Figure 1. Causal model of Chinese consumer satisfaction with sweet cherries.

\section{Materials and methods}

\section{Sample and questionnaire}

A survey was applied to a nonprobability convenience sample (Mora et al., 2011; MartínezCarrasco et al., 2012; Schnettler et al., 2017) that comprised 193 people with Chinese nationality. The survey was developed in Chile in Spanish and then translated to Chinese. It was sent to China, where it was corrected and back-translated to Spanish. The two versions were compared, ensuring their consistency.

The field work was conducted in two phases. The first phase consisted of applying a pretest, where 20 individuals were surveyed in a food market in Beijing, and through this, errors were detected that might affect the result; as a result, these surveys were excluded from the analysis. The second phase consisted of applying the survey on a large scale. To do this, the buyers in the Sanyuanli market, Chaoyang District, Beijing, were considered a sampling unit. This market is large, has a good infrastructure and location, and has a wide range of fruits of various origins and qualities.

The evaluation instrument included questions about perceived extrinsic quality, perceived intrinsic quality and satisfaction. A quantitative method was used to collect data based on a structured survey of 21 questions on a Likert scale (1: not important at all; 5: very important) for perceived quality and five questions on a Likert scale for satisfaction (1: strongly disagree; 5: strongly agree). 
For the perceived intrinsic quality construct, the attributes used were color (Zeithmal, 1988; Schnettler et al., 2010; Mora et al., 2011; Grunert et al., 2015), size (Mora et al., 2011; MartinezCarrasco et al., 2012), aroma (Ragaert et al., 2004; Mora et al., 2011), juiciness (MartínezCarrasco et al., 2012), flavor (Ragaert et al., 2004; Sun and Collins, 2007; Schnettler et al., 2010; Matinez-Carrasco et al., 2012), texture (Ragaert et al., 2004; Ness et al., 2010; Matinez-Carrasco et al., 2012) and freshness (Ragaert et al., 2004; Sun and Collins, 2007; Schnettler et al., 2010; Grunert et al., 2015). The attributes of perceived extrinsic quality considered here were price (Schnettler et al., 2010; Mora et al., 2011, Lee et al., 2015), region of origin (Schnettler et al., 2010; Martinez-Carrasco et al., 2012; Grunert et al., 2015), seller's recommendation (Mora et al., 2011), availability (Mora et al., 2011), quality seals (Verbeke et al., 2010; Grunert et al., 2015) and label type(Martínez-Carrasco et al., 2012). Finally, for satisfaction, the aspects used included the preference of the latest sweet cherries, being satisfied with the product, being satisfied with the seller, and the fulfillment of expectations with regard to the sweet cherries of this country of origin (Sanzo et al., 2003; Espejel et al., 2009; Espejel and Fandos, 2009).

To perform the exploratory factor and confirmatory factor analyses and the structural equations model, the software SPSS Statistics v. 21 was used with Amos, employing maximum likelihood extraction (Loan et al., 2017).

\section{Exploratory factor analysis}

The exploratory analysis of the study involved determining the individual reliability of the indicators obtained from the reduction of dimensions, the Kaiser-Meyer-Olkin (KMO) index and Bartlett's test of sphericity (BTS), which must be significant, i.e., less than 0.05 (Williams et al., 2010).

\section{Confirmatory factor analysis}

In the confirmatory analysis, two construct reliability tests were carried out: the first was Cronbach's alpha, which measures the internal consistency of the constructs individually and must be greater than 0.7 (Loan et al., 2017); however, Cronbach's alpha for each separate factor does not consider the influence of the remaining latent variables. Therefore, the composite reliability (CR) was calculated, which considers the interrelations of the constructs and has a minimum accepted value of 0.7 (Bellini et al., 2017). To obtain the validity of the latent variables, two fundamental analyses were performed: convergent validity and discriminant validity. The convergent validity is verified through the average variance extracted (AVE) of the constructs, with the recommended minimum being 0.5 , which may indicate that the variables explain more than $50 \%$ of the variance of their constructs (Sholekar and Shoghi, 2017). On the other hand, the discriminant validity between constructs was evaluated using the criterion that the square root of the AVE for each construct should be greater than its correlations with all other constructs (Fornell and Larcker, 1981).

\section{Structural equations model}

Once these tests were complete, the goodnessof-fit of the model was estimated. For this study, the following was determined: a) $X^{2} /$ d.f., which according to Schreiber (2017) must be greater than 2 and less than $3, b$ ) the root mean square error of approximation (RMSEA), with the maximum accepted value being less than 0.08 (Browne and Cudeck, 1992), c) the goodness-of-fit index (GFI), which must be greater than 0.9 (Hoyle, 1995), d) the comparative fit index (CFI), which according to Schreiber (2017) must be greater than 0.95, e) the adjusted goodness-of-fit index (AGFI), which must have values over 0.85 (Saba and Vasallo, 2002), and f) the PRatio, which measures the parsimony of the model and must be close to 1 . 
Finally, to test the hypothesis, the critical ratio must be considered, which must a value greater than 1.96 and a P-value less than 0.05 (Sholekar and Shoghi, 2017).

\section{Result and discussion}

The sample presented three important characteristics: most respondents were women over 24 years of age who had high purchasing power (Table 1). Sabbe et al. (2007) conclude that women have a higher degree of acceptance of fresh fruits. In terms of monthly family income, Liu and Niyongira (2017) describe the Chinese consumers with greater purchasing power as tending to choose higher quality products. On the other hand, young people consume the least fresh fruit, and Duan et al. (2017) state that young Chinese adults between 18 and 24 years of age consume fewer than the five of the daily recommended portions of fruits and vegetables.

For the model to be developed correctly, two fundamental phases must be completed in the structural equations: exploratory factor analysis and confirmatory factor analysis. The KMO index obtained for the first analysis was 0.745 , exceeding the minimum of 0.5 established by Williams et al. (2010); therefore, it was feasible to perform a factor analysis with the data. At the same time, the BTS was 0.00 , meaning that the correlation matrix was not an identity matrix. Accordingly, the study determined that the observable variables of medium size (ATRI13) and color (ATRI14) are significant for the construct perceived intrinsic quality and the variables of Chilean origin (ATRI01), delivery time (ATRI08) and price (ATRI09) are significant for the construct perceived extrinsic quality. All variables showed statistical reliability represented by the critical ratio greater than 1.96 and $p$-value less than 0.005 (Table 2). This result confirms that obtained by Grunert et al. (2015), who concluded that Chinese consumers use color as the determinant of
Table 1. Sociodemographic profile of the sample

\begin{tabular}{lccc}
\hline Variable & Item & Frequency & Percentage \\
\hline Gender & Male & 76 & 39.4 \\
& Female & 117 & 60.6 \\
Age & From 18 to 24 & 47 & 24.4 \\
& From 25 to 34 & 71 & 36.8 \\
& From 35 to 50 & 57 & 29.5 \\
& Over 50 & 18 & 9.3 \\
Monthly & Less than $¥ 5000$ & 66 & 34.2 \\
income & & & \\
& From $¥ 5000$ to & 75 & 38.9 \\
& $¥ 7000$ & 52 & 26.9 \\
& More than $¥ 7000$ & 53 & \\
Education & Primary & 14 & 7.3 \\
level & & & \\
& Secondary & 18 & 9.3 \\
& Technical & 57 & 29.5 \\
& University & 104 & 53.9 \\
\hline
\end{tabular}

perceived intrinsic quality. The univariate data in this study reveal that color garnered $92 \%$ of the importance placed by consumers and is also the indicator that had the highest average score (4.60). Sun (2010) determined that the buyers of cherries at online auctions preferred the Chilean product for its medium size and accessible price. In this respect, Lee et al. (2015) report that variable price affects the extrinsic quality of the product, i.e., the higher the price, the better the quality as perceived by Chinese consumers. Chinese consumer preference for imported products over domestic ones can be explained by the current food safety problems that China is experiencing; considerable evidence has been gathered suggesting that food in China is less safe (Sun and Collins 2007; Grunert et al., 2015). Finally, for Chinese consumer satisfaction, the variables belonging to the construct are I prefer the latest sweet cherries (ATRI22), I am satisfied with the product (ATRI23) and I am satisfied with the seller who sold it to me (ATRI24), confirming the food studies conducted by Sanzo et al. (2003), Espejel et al. (2009) and Espejel and Fandos (2009) (Figure 2). With regard to the confirmatory analysis, 
the reliability of the constructs was determined (Table 3). Cronbach's alpha was above 0.7 for the three constructs, verifying that they can be reliably measured individually. At the same time, the composite reliability determined that the constructs are reliable for measurement as a whole. The convergent validity of the construct indicated that the attributes of the latent variables shared more than $50 \%$ of the explained variance, whereas it is deduced from the discriminant validity (Table 4) that the constructs are indeed different from each other.
The goodness of fit of the model is sound and meets the literature guidelines: the discrepancy indicator $X^{2} /$ d.f. $=2.114$, RMSEA $=0.076$, GFI $=0.956$, AGFI $=0.907, \mathrm{CFI}=0.958$ and $\mathrm{PRatio}=0.607$.

In testing the hypothesis (Table 4), it was determined with $95 \%$ confidence $(p<0.05)$ that the perceived intrinsic quality of fresh sweet cherries positively and significantly influences Chinese consumer satisfaction. With this result, hypothesis 2 can be accepted, which confirms what has been reported in other food stud-

Table 2. Reliability of the indicators

\begin{tabular}{|c|c|c|c|}
\hline Proposed construct & Attribute & Code & Critical ratio \\
\hline \multirow{12}{*}{$\begin{array}{l}\text { Perceived extrinsic } \\
\text { quality (PEQ) }\end{array}$} & Chilean origin & ATRI01 & nd \\
\hline & Bulk & ATRI02 & ni \\
\hline & Label & ATRI03 & ni \\
\hline & Parking availability & ATRI04 & ni \\
\hline & Seller recommendation & ATRI05 & ni \\
\hline & Available in supermarkets & ATRI06 & ni \\
\hline & Available in greengrocers & ATRI07 & ni \\
\hline & Delivery time & ATRI08 & $7.265 * * *$ \\
\hline & Price & ATRI09 & $7.176^{* * *}$ \\
\hline & American origin & ATRI10 & ni \\
\hline & Chinese origin & ATRI11 & ni \\
\hline & Quality seal & ATRI12 & ni \\
\hline \multirow{9}{*}{$\begin{array}{l}\text { Perceived intrinsic } \\
\text { quality (PIQ) }\end{array}$} & Medium size & ATRI13 & nd \\
\hline & Color & ATRI14 & $3.444 * * *$ \\
\hline & Large size & ATRI15 & ni \\
\hline & Small Size & ATRI16 & ni \\
\hline & Aroma & ATRI17 & ni \\
\hline & Juiciness & ATRI18 & ni \\
\hline & Flavor & ATRI19 & $\mathrm{ni}$ \\
\hline & Freshness & ATRI20 & ni \\
\hline & Texture & ATRI21 & ni \\
\hline \multirow[t]{5}{*}{ Satisfaction (ST) } & I prefer the latest sweet cherries & ATRI22 & nd \\
\hline & I am satisfied with the product & ATRI23 & $9.108 * * *$ \\
\hline & $\begin{array}{l}\text { I am satisfied with the seller } \\
\text { who sold it to me }\end{array}$ & ATRI24 & $8.672 * * *$ \\
\hline & $\begin{array}{l}\text { I recommend the product to } \\
\text { other people }\end{array}$ & ATRI25 & ni \\
\hline & $\begin{array}{l}\text { My expectations have been } \\
\text { fulfilled with regard to the } \\
\text { sweet cherries of this country } \\
\text { of origin }\end{array}$ & ATRI26 & $\mathrm{ni}$ \\
\hline
\end{tabular}

***Significant below 0.005 . nd: not determined because this regression coefficient was adjusted to 1 to identify the model. ni: not incorporated as a variable to the model because it is nonsignificant. 


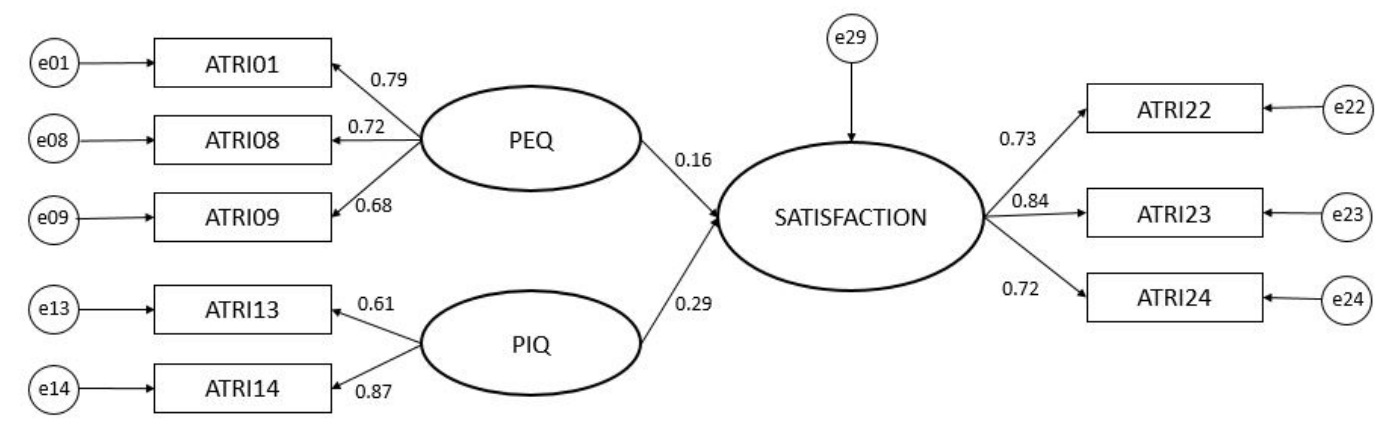

Figure 2. Structural equations model that explains consumer satisfaction with sweet cherries based on perceived extrinsic and intrinsic quality.

Table 3. Reliability and convergent validity of the constructs

\begin{tabular}{lccc}
\hline $\begin{array}{l}\text { Proposed } \\
\text { construct }\end{array}$ & Cronbach's $\alpha$ & $\begin{array}{c}\text { Composite } \\
\text { reliability }\end{array}$ & $\begin{array}{c}\text { Average } \\
\text { variance } \\
\text { extracted }\end{array}$ \\
\hline $\begin{array}{l}\text { Perceived } \\
\text { intrinsic quality }\end{array}$ & 0.712 & 0.732 & 0.601 \\
$\begin{array}{l}\text { Perceived } \\
\text { extrinsic quality }\end{array}$ & 0.769 & 0.774 & 0.535 \\
Satisfaction & 0.804 & 0.808 & 0.585 \\
\hline
\end{tabular}

ies by Espejel et al. (2009) on ham and by Grunert et al. (2015) on pork ribs. By contrast, no evidence was obtained to support the link between extrinsic attributes and the consumer satisfaction of fresh sweet cherries. This result makes it possible to reject hypothesis 1 . In this respect, other studies, such as those conducted by Espejel and Fandos (2009) on wine, have concluded that there is no positive and significant relation between the perceived extrinsic quality and satisfaction; however, Grunert et al. (2015) determined that extrinsic attributes achieve significance in Chinese consumer satisfaction only in a small age group. On the other hand, the coefficient of determination of the endogenous or dependent variables $\left(\mathrm{R}^{2}\right)$ was 0.15 ; that is, the structural model of satisfaction is explained as $15 \%$, an indicator that, according to Falk and Miller (1992), must be higher than $0.1(10 \%)$ to be acceptable.

The limitations of this study, considering the nonprobabilistic nature of the sample, are that the results cannot be generalized and the sample is not representative according to population distribution. Another limitation is the small sample size. Therefore, future studies must include larger samples that permit the differentiation of possible market segments. Nevertheless, this study does provide knowledge of the behavior of Chinese consumers with respect to sweet fruit, an area where there is still little information.

By virtue of the results presented, it may be concluded that consumer satisfaction is positively and significantly influenced by only the quality perceived based on intrinsic attributes.

Table 4. Discriminant validity and hypothesis testing

\begin{tabular}{lccc}
\hline Proposed construct & $\begin{array}{r}\text { Perceived intrinsic } \\
\text { quality }\end{array}$ & $\begin{array}{c}\text { Perceived extrinsic } \\
\text { quality }\end{array}$ & Satisfaction \\
\hline Perceived intrinsic quality & 0.775 & & \\
Perceived extrinsic quality & 0.410 & 0.731 & 0.765 \\
Satisfaction & 0.216 & 0.252 & p-value \\
Hypothesis & & Critical ratio & 0.003 \\
Perceived intrinsic quality $\rightarrow$ Satisfaction & 2.937 & 0.131 \\
Perceived extrinsic quality $\rightarrow$ Satisfaction & 1.511 & \\
\hline
\end{tabular}


A model based on structural equations was identified: it exhibited validity and reliability in its indicators and had a goodness of fit accepted by the literature. Thus, this model could be applied to other studies to examine consumer behavior with certain foods.

The fruit price, product delivery time and Chilean origin are attributes that determine the extrinsic quality as perceived by Chinese consumers; however, these attributes do not significantly affect Chinese consumer satisfaction.

The observable variables color and medium size determine the intrinsic quality as perceived by Chinese consumers, and they also influence satis- faction when consuming sweet cherries positively and significantly.

Chilean exporters should focus their strategies on the intrinsic attributes of the product that satisfy the Chinese consumer, such as color and size, seeking to ensure that these attributes are associated with fruits of Chilean origin. Additionally, postharvest strategies must be strengthened to provide a product with attributes that will satisfy the consumer of this market.

In future investigations, to delve more deeply into the knowledge and impact of the external variables on satisfaction, postharvest product variables such as purchase intention and consumer loyalty could be integrated into the model.

\title{
Resumen
}

\begin{abstract}
A. Chiang, B. Schnettler, M. Mora, y M. Aguilera. 2018. Calidad percibida y satisfacción con cerezas dulces (Prunus Avium L.) en China: Confirmando relaciones a través de ecuaciones estructurales. Cien. Inv. Agr. 45(3): 210-219. En los últimos años Chile se ha constituido en el principal proveedor de cerezas frescas del mercado chino. El objetivo de este trabajo es modelar la satisfacción de consumidores chinos por cerezas frescas, como consecuencia de la calidad percibida a través de atributos intrínsecos y extrínsecos, desarrollando un modelo relacional con dos hipótesis de trabajo. Se aplicaron encuestas a 193 compradores del mercado de Sanyuanli, distrito de Chaoyang, ciudad de Beijing, considerando preguntas cerradas medidas en escala de Likert. Para desarrollar un modelo que cumpla con el objetivo señalado se empleó un análisis factorial exploratorio y posteriormente para confirmar las relaciones un sistema de ecuaciones estructurales, presentando un análisis de bondad de ajuste adecuado para aceptar el modelo según literatura. Entre los resultados principales, se determinó con un ratio crítico de 2.937 y un P-value de 0.003 que la satisfacción de los consumidores de cerezas frescas se explica a partir de la calidad percibida intrínseca, donde el tamaño mediano y el color corresponden a los atributos determinantes de ésta y el precio, el origen chileno y el tiempo de entrega del producto explican la calidad percibida extrínseca. Finalmente, se concluye que la calidad intrínseca influye de forma positiva y significativa en la satisfacción de los consumidores chinos de cerezas frescas en contraste con la calidad percibida extrínseca, la que no logra ser estadísticamente significativa.
\end{abstract}

Palabras clave: Calidad percibida, cerezas dulces, modelos de ecuaciones estructurales, satisfacción. 


\section{References}

Akdeniz, B., R. Calantone, and C. Voorhees. 2013. Effectiveness of marketing cues on consumer perception of quality: The moderating roles of brand reputation and third-party information. Psychology \& Marketing 30:76-89.

Bellini, S., M. Cardinali, and B. Grandi. 2017. A structural equation model of impulse buying behaviour in grocery retailing. Journal of Retailing and Consumer Services 36:164-171.

Browne, M. W., and R. Cudeck. 1992. Alternative ways of assessing model fit. In: Bollen, K. A., and J. S. Long (eds.). Testing structural equation models. Sage, Newbury Park, CA. p. $136-162$.

Cheng, J., E. Wang, J. Lin, L. Chen, and W. Huang. 2008. Do extrinsic cues affect purchase risk at international e-tailers: The mediating effect of perceived e-tailer service quality. Journal of Retailing and Consumer Services 15:420-428.

Churchill, G., and C. Surprenant. 1982. An investigation into the determinants of customer satisfaction. Journal of Marketing research 19:491-504.

Cronin, J., M. Brady, and G. Hult. 2000. Assessing the effects of quality, value and customer satisfaction on consumer behavioural intcronientions in service environments. Journal of Retailing 76:193-218.

Du, H., L. Li, D. Bennett, Y. Guo, I. Turnbull, L. et al. 2017. Fresh fruit consumption in relation to incident diabetes and diabetic vascular complication: A 7-y prospective study of 0.5 million Chinese adults. PLoS Medicine 14: e1002279.

Duan, Y., J. Wienert, C. Hu, G. Si, and S. Lippke. 2017. Web-Based Intervention for Physical Activity and Fruit and Vegetable Intake Among Chinese University Students: A Randomized Controlled Trial. Journal of medical Internet research 19: e106.

Ergönül, B. 2013. Consumer awareness and perception to food safety: A consumer analysis. Food Control 32:461-471.

Espejel, J., and C. Fandos. 2009. Wine marketing strategies in Spain: A structural equation approach to consumer response to protected desig- nations of origin (PDOs). International Journal of Wine Business Research 21:267-288.

Espejel, J., C. Fandos, and C. Flavián. 2009. The influence of consumer involvement on quality signals perception: An empirical investigation in the food sector. British Food Journal 111:1212-1236.

Falk, R. and N. Miller. 1992. A primer for soft modeling. University of Akron Press.

Fornell, C., and D. Larcker. 1981. Structural equation models with unobservable variables and measurement error: Algebra and statistics. Journal of Marketing Research 18:382-388.

Grunert, K., T. Perrea, Y. Zhou, G. Huang, B. Sørensen, and A. Krystallis. 2011. Is food-related lifestyle (FRL) able to reveal food consumption patterns in non-Western cultural environments? Its adaptation and application in urban China. Appetite 56:357-367.

Grunert, K., S. Loose, Y. Zhou, and S. Tinggaard. 2015. Extrinsic and intrinsic quality cues in Chinese consumers purchase of pork ribs. Food Quality and Preference 42:37-47.

Hoyle, R. 1995. Structural Equation Modeling: Concepts, Issues, and Applications. Sage Publication Inc.

Lee, P., K. Lusk, M. Mirosa, and I. Oey. 2015. An attribute prioritization-based segmentation of the Chinese consumer market for fruit juice. Food Quality and Preference 46:1-8.

Liu A., and R. Niyongira. 2017. Chinese consumers food purchasing behaviors and awareness of food safety. Food Control 79:185-191.

Loan, L., H. Nomura, Y. Takahashi, and M. Yabe. 2017. Psychological driving forces behind households' behaviors toward municipal organic waste separation at source in Vietnam: a structural equation modeling approach. Journal of Material Cycles and Waste Management 19:1052-1060.

Martínez-Carrasco, L., M. Brugarolas, A. MartínezPoveda, J. Ruiz, and S. García-Martínez. 2012. Modelling perceived quality of tomato by structural equation analysis. British Food Journal 114:1414-1431.

Mora, M., J. Espinoza, B. Schnettler, G. Echeverría, S. Predieri, and R. Infante. 2011. Perceived qual- 
ity in fresh peaches: an approach through structural equation modeling. Ciencia e Investigación Agraria 38:179-190.

Ness, M. R., M. B., Ness, E. Oughton, C. Ritson, and E. Ruto. 2010. Modelling consumer behavioural intentions towards food with implications for marketing quality low-input and organic food. Food Quality and Preference 21:100-111.

ODEPA. 2017. Fresh Fruit Newsletter. Office of Agricultural Studies and Policies ODEPA of the Ministry of Agriculture, Santiago, Chile. https://app.powerbi.com/view?r=eyJrIjoiYjE2NjRjYWItZWY2Yi00OGMyLTgyODUtMDZmOTFiZDkxYTYxliwidCI6IjMzYjdmNzA3LTZINmYtNDJkMi04ZDZmLTk4YmZmOWZiN WZhMCIsImMiOjR9 (accessed 25 Mar. 2017).

Oliver, R. 2010. Satisfaction: A behavioral perspective on the consumer. ME Sharpe.

Olsen, S. 2002. Comparative evaluation and relationship between quality, satisfaction and repurchase loyalty. Journal of the Academy of Marketing Science 30:240-249.

Olsen, S., J. Wilcox, and U. Olsson. 2005. Consequences of ambivalence on satisfaction and loyalty. Psychology \& Marketing. 22:247-269.

Olson, J., and J. Jacoby. 1972. Cue utilization in the quality perception process. In: Proceedings of the Third Annual Conference of the Association for Consumer Research. ed. M. Venkatesan: Association for Consumer Research, Chicago, IL. p. 167-179.

PROCHILE. 2012. Cherry Market Study in China. Santiago, Chile. http://www.prochile.gob.cl/wpcontent/files_mf/documento_05_22_12170704. pdf (accessed 9 Nov. 2016).

Ragaert, P., W. Verbeke, F. Devlieghere, and J. Debevere. 2004. Consumer perception and choice of minimally processed vegetables and packaged fruits. Food Quality and Preference 15:259-270.

Saba, A. and M. Vasallo. 2002. Consumer attitudes toward the use of gene technology in tomato production. Food Quality and Preference 13:13-21.

Sabbe, S., W. Verbeke, and P. Van Damme. 2007. Familiarity and purchasing intention of Belgian consumers for fresh and processed tropical fruit products. British Food Journal 110:805-818.
Sanzo, M., A. del Río, V. Iglesias, and R. Vazquez. 2003. Attitude and satisfaction in a traditional food product. British Food Journal 105:771-790.

Schnettler, B., D. Fica, N. Sepúlveda, J. Sepulveda, and M. Denegri. 2010. Valuation of Intrinsic and Extrinsic Attributes on the Purchase of Beef in Southern Chile. Revista Científica 20:101-109

Schnettler, B., G. Lobos, M. Lapo, C. Adasme, and C. Hueche. 2017. Satisfaction with life and foodrelated life in Ecuadorian older adults-related. Nutrición Hospitalaria 34:65-72.

Schreiber, J. 2017. Update to core reporting practices in structural equation modeling. Research in Social and Administrative Pharmacy 13:634-643.

Sholekar, S., and B. Shoghi. 2017. The Impact of Organizational Culture on Organizational Silence and Voice of Faculty Members of Islamic Azad University in Tehran. Iranian Journal of Management Studies 10:113-142.

Sun, C. 2010. The impact of auction characteristics on prices of agricultural products traded online: evidence from cherries. Agricultural Economics 41:587-594.

Sun, X., and R. Collins. 2007. The application of fuzzy logic in measuring consumption values: Using data of Chinese consumer buying imported fruit. Food quality and preference 18:576-584.

Tuu, H., S. Olsen, and P. Linh. 2011. The moderator effects of perceived risk, objective knowledge and certainty in the satisfaction-loyalty relationship. Journal of Consumer Marketing. 28:363-375.

Verbeke, W., L. Van Wezemael, M. de Barcellos, J. Kügler, J. Hocquette, Ø. Ueland, and K. Grunert. 2010. European beef consumers' interest in a beef eating-quality guarantee: insights from a qualitative study in four EU countries. Appetite 54:289-296.

Williams, B., T. Brown, and A. Onsman. 2010. Exploratory factor analysis: A five-step guide for novices. Journal of Emergency Primary Health Care 8:1-13.

Zeithaml, V. 1988. Consumer Perceptions of Price, Quality, and Value: A Means-End Model and Synthesis of Evidence. Journal of Marketing 52:2-22. 